\title{
Transient kinetics of toluene partial oxidation over V/Ti oxide catalysts
}

\author{
Dmitri A. Bulushev, Lioubov Kiwi-Minsker*, Albert Renken \\ Institute of Chemical Engineering, Swiss Federal Institute of Technology, CH-1015 Lausanne, Switzerland
}

\begin{abstract}
Transient kinetics in the toluene oxidation over V/Ti oxide catalysts prepared by grafting and impregnation have been compared. $\mathrm{V}^{4+}$ cations are supposed to be the sites for the formation of electrophilic oxygen species participating in deep oxidation. Another oxygen species (probably nucleophilic) present on the oxidised catalyst surface are responsible for benzaldehyde formation. Selectivity of $80-100 \%$ can be obtained during the initial period of the reaction on the grafted catalysts in the presence of gaseous oxygen and during the interaction of toluene (without $\mathrm{O}_{2}$ in the mixture) with partially reduced catalysts. (C) 2000 Elsevier Science B.V. All rights reserved.
\end{abstract}

Keywords: Transient response techniques; V/Ti oxide catalysts; Toluene partial oxidation

\section{Introduction}

The unique catalytic properties of vanadia supported on $\mathrm{TiO}_{2}$ have attracted a lot of interest due to their commercial application in oxidation processes $[1,2]$. It is known that the performance of V/Ti oxide catalysts depends on the support properties $\left(\mathrm{TiO}_{2}\right.$ rutile or anatase crystallographic modification, impurities, etc.), degree of $\mathrm{TiO}_{2}$ coverage by vanadia and addition of promoters. The molecular structures of the surface vanadia species seem to determine their reactivity/selectivity in oxidation reactions and have been intensively investigated during the last 10 years. Monomeric $\mathrm{VO}_{4}$ and polymeric $\left(\mathrm{VO}_{x}\right)_{n}$ species in the two-dimensional vanadia layer were identified by different techniques [1-4]. Bulk $\mathrm{V}_{2} \mathrm{O}_{5}$ (crystallites or amorphous) is also present above the monolayer

\footnotetext{
* Corresponding author. Tel.: +41-21-693-31-82; fax: +41-21-693-31-90

E-mail address: lioubov.kiwi-minsker@epfl.ch (L. Kiwi-Minsker).
}

coverage [1-4]. Besides different structural (lattice) nucleophilic oxygen species $\left(\mathrm{O}^{2-}\right)$, electrophilic anion radical oxygen species $\left(\mathrm{O}^{-}, \mathrm{O}_{2}{ }^{-}\right)$with high reactivity were detected on the surface of oxide catalysts [1,5-8]. According to [6-8], $\left(\mathrm{O}^{2-}\right)$ species are mainly responsible for partial oxidation of hydrocarbons, while $\left(\mathrm{O}^{-}, \mathrm{O}_{2}{ }^{-}\right)$species are assumed to be involved in deep oxidation leading to $\mathrm{CO}_{x}$ product formation. Partial toluene oxidation has been studied earlier in the steady state conditions $[1,9,10]$. Participation of the electrophilic oxygen species is also considered in this reaction by some researchers [11].

The oxidation state and molecular structure of vanadia species are influenced upon different environments (oxidative, reductive, etc.) and are dynamic in character. Transient response techniques with continuous monitoring of composition of the gaseous phase is a powerful tool for the investigation of the reaction steps and dynamics of the catalyst surface transformations under the influence of the gaseous media [12-14]. Clarification of reactivity of oxygen 
species is an important question for the design of the catalysts.

To elucidate the mechanism of the oxygen species formation and their reactivity, the transient kinetics of the toluene oxidation was compared over catalysts with different degree of titania coverage by vanadia and after different pre-treatments. To understand the effect of the presence of bulk vanadia, the catalytic properties of the grafted catalysts, prepared by vapour deposition of $\mathrm{VOCl}_{3}$, and the catalyst prepared by standard impregnation method were studied.

\section{Experimental}

$\mathrm{TiO}_{2}$ (100\% anatase, Aldrich) was used as a support for the V/Ti catalysts. Grafted catalysts with 0.27 , 0.47 and 0.57 wt.\% V content were prepared by 2 , 5 and 10 operations of $\mathrm{VOCl}_{3}$ vapour deposition on the surface of $\mathrm{TiO}_{2}$. The coverage by vanadia species corresponds to $0.35,0.62$ and 0.75 monolayers (1 monolayer $=1 \times 10^{19}$ atom $\left.\mathrm{V} / \mathrm{m}^{2}\right)$. These catalysts according to the Raman and HRTEM study did not contain bulk $\mathrm{V}_{2} \mathrm{O}_{5}$. The impregnated catalyst (2.8 wt.\% $\mathrm{V}$ corresponding to 3.7 monolayers) was prepared from the aqueous solution of vanadium oxalate. The catalysts were calcinated in air at $723 \mathrm{~K}$ for $2 \mathrm{~h}$ before the study. Their specific surface area was equal to $9 \mathrm{~m}^{2} / \mathrm{g}$.

The kinetic studies were performed in the experimental set-up described in $[13,15]$. The installation allowed performing a quick switch from one flow to another. A Balzers QMG-421 mass spectrometer and a Perkin-Elmer Autosystem XL gas chromatograph were used for the gas phase analysis. Benzoic acid (BAc) was detected only by gas chromatography. The loading of the catalyst and the gas flow were maintained constant throughout the study at $1 \mathrm{~g}$ and $1 \mathrm{ml} / \mathrm{s}$ (STP), respectively.

The catalysts were pre-treated in $\mathrm{O}_{2} \quad(20 \mathrm{vol} . \%$ $\mathrm{O}_{2}$ in $\mathrm{Ar}$ ) at $673 \mathrm{~K}$ for $0.5 \mathrm{~h}$ (oxidised catalyst) before every run. After the pre-treatment the temperature was decreased as necessary and the flow was quickly switched to the mixture of $2 \mathrm{vol} . \%$ toluene plus 40 vol. $\% \mathrm{O}_{2}$ in $\mathrm{Ar}$ or after a purge by $\mathrm{Ar}$ to the mixture of 2 vol.\% toluene in Ar. To prepare a reduced catalyst the oxidised catalyst was treated by $\mathrm{H}_{2}\left(15 \mathrm{vol} . \% \mathrm{H}_{2}\right.$ in $\left.\mathrm{Ar}\right)$ at $673 \mathrm{~K}$ for $0.5-1 \mathrm{~h}$.

\section{Results}

\subsection{Interaction of toluene with the oxidised catalysts}

A series of experiments was performed on the toluene (without $\mathrm{O}_{2}$ in gas-phase) interaction with the oxidised catalysts (Fig. 1). No BAc formation was observed in these experiments. The concentration of $\mathrm{CO}_{2}$ increases at the beginning passes through a maximum and then strongly decreases in time over both catalysts. The total amount of oxygen removed in the form of $\mathrm{CO}_{2}$ over the impregnated catalyst is higher than that from the grafted catalyst and corresponds to $3 \times 10^{17}$ and $1 \times 10^{17}$ atom $\mathrm{O} / \mathrm{m}^{2}$, respectively.

Concentration of BA formed over the impregnated catalyst is also higher than over the grafted catalyst (Fig. 1). BA was observed in the gas phase for a much longer time (>20 min) than $\mathrm{CO}_{2}$. The BA concentration finally decreases due to the diminishing concentration of active oxygen sites. This behaviour points out that different oxygen sites are responsible for $\mathrm{CO}_{2}$ and BA formation. The decrease in the amount of oxygen in the catalyst should be accompanied by the reduction of the $\mathrm{V}^{5+}$ to the vanadium state with a lower oxidation degree.

\subsection{Interaction of toluene with the reduced catalysts}

The interaction of toluene (without $\mathrm{O}_{2}$ ) was also performed with the catalysts pre-treated in reductive atmosphere $\left(\mathrm{H}_{2}\right)$. No formation of the gaseous $\mathrm{CO}_{2}$ was observed at $573 \mathrm{~K}$ in these runs over both grafted and impregnated catalysts. For the reduced impregnated catalyst, BA was formed at $573 \mathrm{~K}$ (Fig. 2), but with two times lower concentration than over the oxidised catalyst (Fig. 1b) whereas no BA is detected over the grafted catalyst. The difference in the transient behaviour of the reduced grafted and impregnated catalysts can be explained by the presence of bulk $\mathrm{V}_{2} \mathrm{O}_{5}$ in the impregnated catalyst. Temperature programmed reduction data [1-3] show that bulk $\mathrm{V}_{2} \mathrm{O}_{5}$ is reduced in $\mathrm{H}_{2}$ at a higher temperature than the monolayer $\mathrm{V}$ species present in the $\mathrm{V} / \mathrm{Ti}$ oxide catalysts. Probably, the bulk $\mathrm{V}_{2} \mathrm{O}_{5}$ in the impregnated catalyst is not completely reduced under the used reductive conditions and participates in BA formation. 

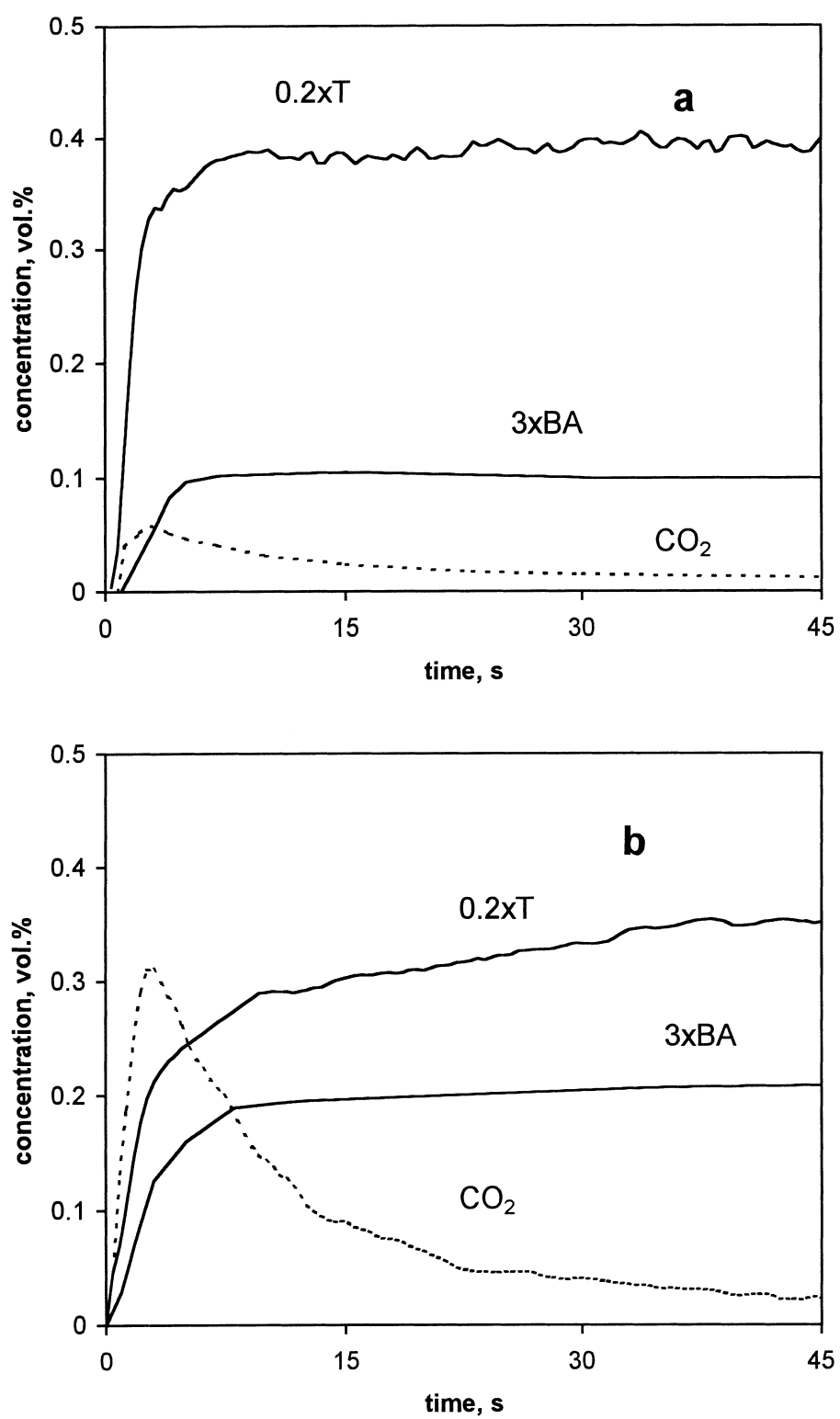

Fig. 1. Response curves obtained after a switch of Ar flow to the toluene/Ar flow on the oxidised 0.57 wt.\% (a) and 2.8 wt.\% (b) $\mathrm{V} / \mathrm{TiO} 2$ catalysts at $573 \mathrm{~K}$.

\subsection{Interaction of the toluene/ $\mathrm{O}_{2}$ mixture with the} oxidised and reduced catalysts

Fig. 3 compares the dynamics of reaching the steady state in the reaction after a switch of the $\mathrm{O}_{2} / \mathrm{Ar}$ mixture to the toluene $/ \mathrm{O}_{2} / \mathrm{Ar}$ mixture over grafted (a) and impregnated catalysts (b). For both catalysts, benzalde- hyde (BA) appears in the gas phase simultaneously with toluene. The shape of BA curve is similar in form to the toluene curve for the both catalysts. $\mathrm{CO}_{2}$ and $\mathrm{H}_{2} \mathrm{O}$ (not shown) concentrations reach the steady state values slower than BA. The transient period in the $\mathrm{CO}_{2}$ formation is much more pronounced on the grafted catalyst (Fig. 3a) than on the impregnated one 


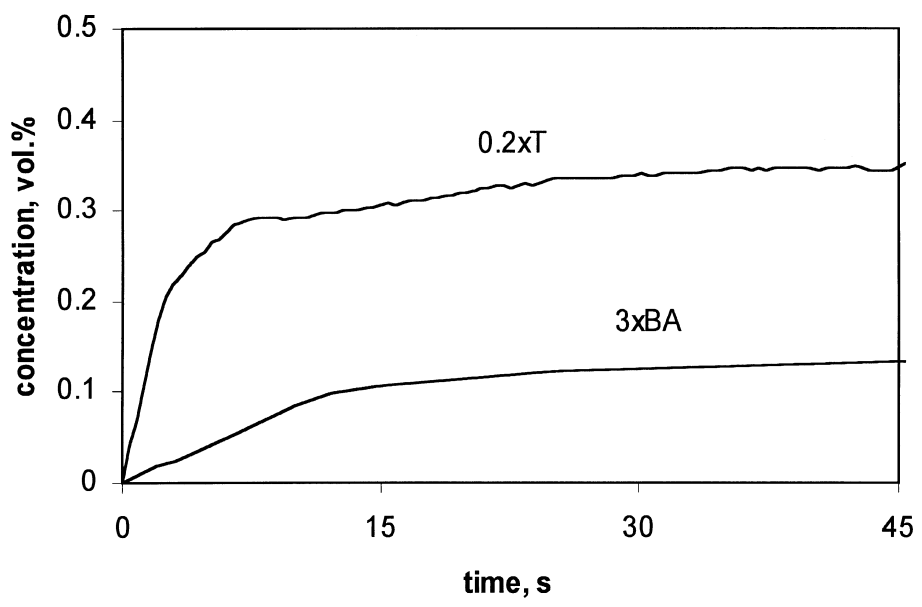

Fig. 2. Response curves obtained after a switch of Ar flow to the toluene/Ar flow on the reduced $2.8 \mathrm{wt} . \% \mathrm{~V} / \mathrm{TiO}_{2}$ catalyst at $573 \mathrm{~K}$.
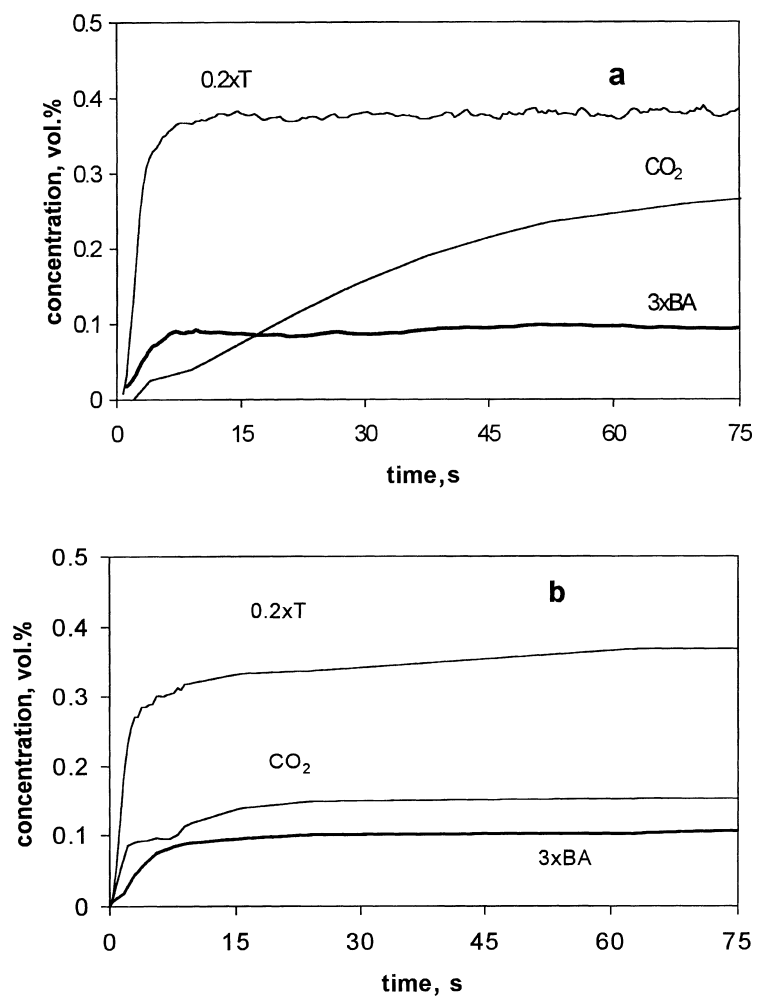

Fig. 3. Response curves obtained after a switch of the $\mathrm{O}_{2} / \mathrm{Ar}$ flow to the toluene $/ \mathrm{O}_{2} / \mathrm{Ar}$ flow on the oxidised $0.57 \mathrm{wt} . \%$ (a) and 2.8 wt. $\%$ (b) $\mathrm{V} / \mathrm{TiO}_{2}$ catalysts at $523 \mathrm{~K}$.
(Fig. 3b). BAc formation was detected for the impregnated catalyst with a selectivity of $30 \%$, but was not detected for the grafted catalyst. On the grafted catalyst, a higher initial selectivity towards BA (80-100\%) is reached than under steady state conditions $(40 \%)$.

The interaction of the toluene/ $\mathrm{O}_{2}$ mixture with the reduced catalysts was also studied (Fig. 4). The reductive pre-treatment was performed by toluene $(523 \mathrm{~K}$, $20 \mathrm{~min}$ ) and $1.1 \times 10^{18}$ atom $\mathrm{O} / \mathrm{m}^{2}$ was removed from the catalyst in the form of gaseous products. As $\mathrm{H}_{2}$ is less reactive than toluene a higher temperature of $598 \mathrm{~K}$ was applied to reduce partially the catalyst. It is seen that $\mathrm{CO}_{2}$ reaches the steady state very quickly if the catalyst is preliminary reduced by toluene (Fig. 4, curve a). On the hydrogen reduced catalyst, $\mathrm{CO}_{2}$ evolution is at first, fast but slows down approximately after $10 \mathrm{~s}$ (Fig. 4, curve b). Steady state is not reached within $10 \mathrm{~min}$. The dynamic behaviour of the $\mathrm{CO}_{2}$ production after oxidative pre-treatments of the catalyst is completely different (Fig. 4, curve c). In contrary to deep oxidation, no differences in the BA response curves were found for differently pre-treated catalysts (curve $d$ ). This is a further indication that the oxygen sites for BA formation are different from the ones of $\mathrm{CO}_{2}$ formation.

Fig. 5 shows that the transient behaviour of $\mathrm{CO}_{2}$ production is also strongly dependent on the $\mathrm{V}$ content of the oxidised catalysts. With decreasing $\mathrm{V}$ loading on the grafted catalyst, the S-shape of the concentration-time curves becomes more and more 


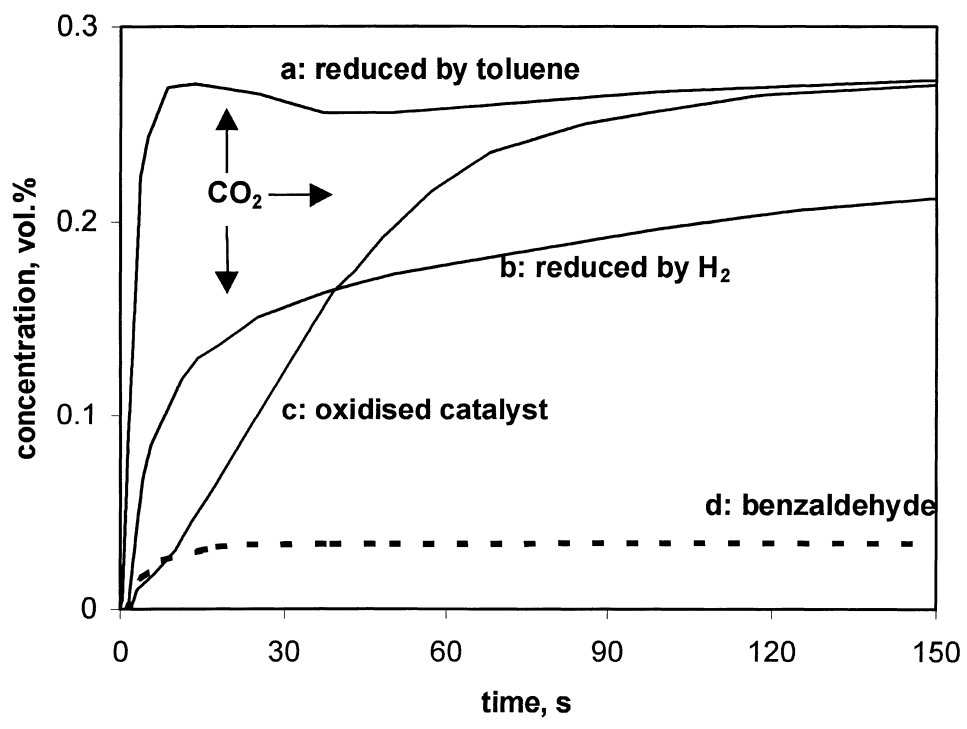

Fig. 4. Response curves of $\mathrm{CO}_{2}(\mathrm{a}-\mathrm{c})$ and benzaldehyde (d), obtained after a switch of Ar flow to the toluene/O $/ 2 / \mathrm{Ar}$ flow on the oxidised (c, d), reduced by toluene $(523 \mathrm{~K}, 20 \mathrm{~min})(\mathrm{a}, \mathrm{d})$ and reduced by hydrogen $(598 \mathrm{~K}, 20 \mathrm{~min})(\mathrm{b}, \mathrm{d}) 0.57 \mathrm{wt} . \% \mathrm{~V} / \mathrm{TiO}_{2}$ catalyst at $523 \mathrm{~K}$.

pronounced. These curves clearly indicate the formation of intermediate surface sites or intermediates during the transient period. For the impregnated catalyst, the $\mathrm{CO}_{2}$ production is observed immediately after switching to the toluene $/ \mathrm{O}_{2}$ mixture indicating that the necessary sites for deep oxidation exist already initially on the catalyst surface.

\section{Discussion}

With the increase of the vanadium concentration in the catalysts, the increase of the ratio of the polymeric and bulk vanadia structures takes place $[3,4]$. In the studied samples, the three-dimensional bulk vanadia is present only in the impregnated catalyst.

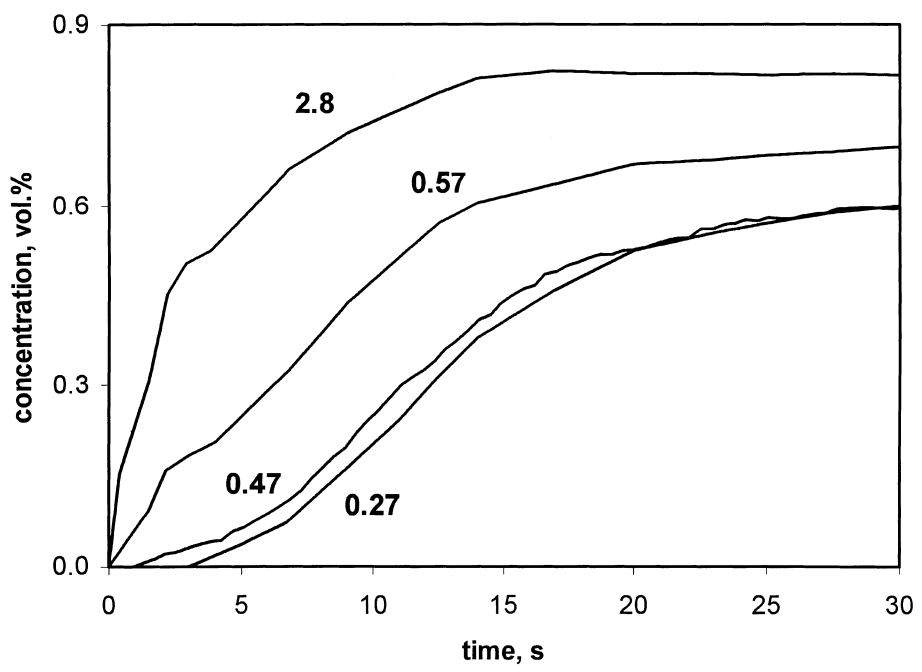

Fig. 5. Response curves of $\mathrm{CO}_{2}$ obtained after a switch of the $\mathrm{O}_{2} / \mathrm{Ar}$ flow to the toluene/ $\mathrm{O}_{2} / \mathrm{Ar}$ flow on the oxidised $\mathrm{V} / \mathrm{TiO} \mathrm{O}_{2}$ catalysts at $573 \mathrm{~K}$ (vanadium content is pointed out). 


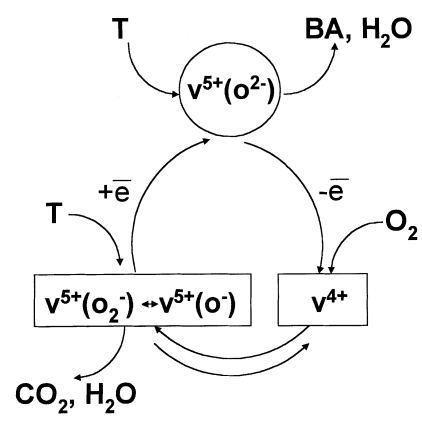

Fig. 6. Oxidation-reduction cycle in the toluene oxidation for monolayer $\mathrm{V} / \mathrm{TiO}_{2}$ catalyst.

The performed dynamic studies of toluene oxidation in the presence of gaseous oxygen and without it confirm that different active sites are responsible for the partial and deep oxidation. Benzaldehyde is formed by the participation of the structural oxygen present in the catalyst. This oxygen can be assigned to oxygen species of nucleophilic type [6,7]. Taking into account that at a low coverage by vanadium, monomeric sites $\left(\mathrm{VO}_{4}\right)$ are mainly present on the surface and the fact of low reactivity of the terminal oxygen in $\mathrm{V}=\mathrm{O}$ groups in comparison to the bridging oxygen species [3], it is possible to conclude that the bridging oxygen in $\mathrm{V}-\mathrm{O}-\mathrm{Ti}$ groups is important for benzaldehyde formation.

The study of the transient behaviour of the reaction on the grafted catalysts with monolayer vanadia species and impregnated catalyst with the bulk vanadia elucidated large differences in the dynamics of $\mathrm{CO}_{2}$ formation. The S-shape of the concentration-time curve for oxidised grafted catalysts indicates the formation of intermediate sites or intermediates. The electrophilic oxygen species can be considered as the main intermediates in deep toluene oxidation. They seem to be formed by the participation of the reduced vanadium sites. This explains the observed higher initial oxidation rate on the reduced catalysts compared to the oxidised one (Fig. 4). The following simplified scheme (Fig. 6) is supposed to explain the experimental data for the grafted catalysts.

The concentration of the electrophilic oxygen species increases with the vanadium content probably due to the formation of polymeric and bulk vanadia species. For the grafted catalyst with low vanadium content, no electrophilic oxygen species are present on the surface. Thus, toluene interacts with the nucleophilic structural oxygen species $\mathrm{V}^{5+}\left(\mathrm{O}^{2-}\right)$ forming benzaldehyde and water (Fig. 6). $\mathrm{V}^{4+}$ sites are also formed. Adsorption of oxygen does not result in immediate reoxidation of the catalyst with the formation of the structural oxygen species. It proceeds via several steps involving the electrophilic oxygen species [5-8]. These species are stabilised by $\mathrm{V}^{5+}$ cations. Their further transformation proceeds either in the direction of deep oxidation during the interaction of toluene and with the formation of $\mathrm{V}^{4+}$ sites, or in the direction of the formation of the structural oxygen species active for partial oxidation. The slow process for $\mathrm{CO}_{2}$ formation (Fig. 4, curve b) observed for the catalyst reduced by hydrogen can be explained by the fact that the reduction takes place not only up to $\mathrm{V}^{4+}$ state, but more deeply to $\mathrm{V}^{3+}$ one. It seems that in the presence of the reaction mixture, these sites can only be slowly transformed into the $\mathrm{V}^{4+}$ sites.

High selectivity can be reached only under dynamic conditions on the oxidised grafted catalysts because the formation of the electrophilic oxygen species active in deep oxidation is a relatively slow process.

\section{Conclusions}

The transient behaviour of the grafted catalysts during the interaction with toluene has indicated that electrophilic species $\left(\mathrm{O}^{-}, \mathrm{O}_{2}{ }^{-}\right)$are formed as intermediates during the reoxidation of $\mathrm{V}^{4+}$ to $\mathrm{V}^{5+}$ in the presence of gaseous oxygen. Nucleophilic structural oxygen species mainly participate in the formation of benzaldehyde. Initial selectivity towards benzaldehyde up to $100 \%$ was obtained under transient conditions over grafted catalysts. An oxidation-reduction catalytic cycle is proposed which allows an explanation on the experimental results.

\section{Acknowledgements}

Authors thank the EU Inco-Copernicus programme for the financial support, Dr. A.A. Ivanov and Dr. S.I. Reshetnikov (Boreskov Institute of Catalysis, Russia) for granting the catalysts, E. Aebischer and F.-R. Balestra for their participation in experiments. 


\section{References}

[1] B. Grzybowska-Swierkosz, Appl. Catal. 157 (1997) 263.

[2] J.C. Vedrine (Ed.), Catal.Today 20 (1994).

[3] I.E. Wachs, B.M. Weckhuysen, Appl. Catal. 157 (1997) 67.

[4] G.T. Went, L.-J. Leu, A.T. Bell, J. Catal. 134 (1992) 479.

[5] V.A. Shvets, V.B. Kazanskii, J. Catal. 25 (1972) 123.

[6] A. Bielanski, J. Haber, Oxygen in Catalysis, Dekker, New York, 1991, pp. 392-403.

[7] J. Haber, Stud. Surf. Sci. Catal. 110 (1997) 1.

[8] V.D. Sokolovskii, Catal. Rev.-Sci. Eng. 32 (1990) 1.

[9] A.J. van Hengstum, J.G. van Ommen, H. Bosch, P.J. Gellings, Appl. Catal. 8 (1983) 369.
[10] B. Jonson, B. Rebenstorf, R. Larsson, S.L.T. Andersson, J. Chem. Soc., Faraday Trans. 184 (1988) 3547.

[11] B.I. Whittington, J.R. Anderson, J. Phys. Chem. 97 (1993) 1032.

[12] A. Renken, Int. Chem. Eng. 33 (1993) 61.

[13] D.A. Bulushev, L. Kiwi-Minsker, A. Renken, Catal. Today 57 (2000) 231.

[14] S. Golay, L. Kiwi-Minsker, R. Doepper, A. Renken, Chem. Eng. Sci. 54 (1999) 3593.

[15] F.-R. Balestra, Oxydation partialle du toluene sur des catalyseurs vanadium/titane. Travail pratique de diplome, EPFL, Lausanne, 1999. 